\title{
A Tangible Interface System for People with Down Syndrome
}

\author{
Gabriel dos Santos Dourado \\ Pontifícia Universidade Católica \\ de Goiás, PUC Goiás \\ Goiânia/Go Brasil
}

\author{
Kárita Cecília Rodrigues \\ Silva \\ Pontifícia Universidade Católica \\ de Goiás, PUC Goiás \\ Goiânia/Go Brasil
}

\author{
Josef Augusto Oberdan \\ Souza Silva \\ Pontifícia Universidade Católica \\ de Goiás, PUC Goiás \\ Goiânia/Go Brasil
}

\author{
Juliana Santos de Souza \\ Hannum \\ Pontifícia Universidade Católica \\ de Goiás, PUC Goiás \\ Goiânia/Go Brasil
}

\author{
Ariane Ruben Calaça Di \\ Menezes \\ Pontifícia Universidade Católica \\ de Goiás, PUC Goiás \\ Goiânia/Go Brasil
}

\author{
Talles Marcelo Gonçalves \\ de Andrade Barbosa \\ Pontifícia Universidade Católica \\ de Goiás, PUC Goiás \\ Goiânia/Go Brasil
}

\begin{abstract}
In general, people with Down syndrome have cognitive limitations and motor difficulties that may compromise the individual's development throughout life. It is due to the genetic condition that imposes peculiarities, such as low muscle tone and difficulty in learning, making it difficult to understand and interact with and around the environment. However, the use of new technologies proves to be a promising route because it offers new stimuli that can be used as reinforcers in rehabilitation, training, and entertainment activities. An example is a provision and use of systems with tangible interfaces, whose interaction between the user and the machine happens through touch. It promotes proprioception, incites attention, interest, and concentration. This work describes the development and evaluation of a computational system with a tangible interface, called 3D Sandplay. This system offers a sandbox, which enables user interaction with the virtual world, amplified by Augmented Reality, for creating scenarios and understanding abstract concepts. 3D Sandplay was evaluated by a group of people with Down syndrome in three distinct activities and, in addition to achieving the events, the interest, attention, and resistance to complete the activities were evaluated. All research volunteers are students of the Alfadown project, an extension project maintained by PUC Goiás. Results have shown that 3D Sandplay is a tool that can contribute to the cognitive and motor development of children, adolescents, and adults with Down syndrome.
\end{abstract}

\section{Keywords}

Down Syndrome, Tangible Interface, Augmented Reality.

\section{INTRODUCTION}

Augmented Reality (AR) proposes the integration of realworld elements with the virtual world. For this, the capture of gestures, movements, or touches can be transformed into electronic information. In a complementary way, a Tangible Interface (TI) is one that allows interaction between the user and the computer system through touch [1].

Sandplay is a tool commonly used by health professionals for therapy, entertainment, and teaching. The apparatus consists of a sandbox and a set of archetypes, whose purpose is to offer the user the environment and the objects to construct scenarios or narratives related to the subjectivity itself. According to Kalff, the central aspect of the sand play is to provide the patient with free and protected space [2]. It promotes synesthesia and facilitates interaction between the patient and the therapist. According to Antunes and Vicentini [3], many reflexes are triggered tactilely by proprioception, recognition of the spatial location of the body. The tactile system provides information on what is in contact with the skin, temperature, texture, shape, and movement.

The use of AR with support in TI has led to the emergence of a new technology known as Augmented Reality SandBox or simply ARSandBox. This technology extends the functionality of a game in the sand, by the possibility of multimedia projection, in three dimensions, triggered by the touch. ARSandbox systems have become famous for topography learning and entertainment. For example, the work developed by CHUTCHOMCHUEN [4] presents the results of a study carried out with elementary school students, in which the participants used an ARSandBox to learn Geography concepts. Because of this, it is speculated that this technology can also contribute to the training of vulnerable people, particularly those with Autism Spectrum Disorder (ASD) and people with Down syndrome.

Down Syndrome (DS) is a disorder of genetic origin that causes cognitive and motor difficulties to affected individuals, in addition to anatomical differences when these individuals are compared to typical individuals. In general, people with DS present deficits in learning and muscle hypotonia, leading to delays in intellectual and motor development. Customized activities and the use of technological tools that stimulate attention, engagement, and proprioception can contribute to the cognitive, emotional, and motor development of individuals with DS. Faced with this, the Pontifical Catholic University of Goiás (PUC Goiás) maintains an extension project, called Alfadown. The goal of the Alfadown project is to facilitate literacy and social inclusion of people with DS, with access to computer resources [5]. Recently, in the framework of the Alfadown project, applications for the mobile platform with support for biofeedback [6] and systems with augmented reality were developed, introduced and evaluated through tangible and fluid interfaces [7]. 
In this paper is presented an ARSandplay system called 3D Sandplay. It provides a tangible interface that can be used as a reinforcer for intellectual development and motor coordination. For this, it stimulates the touch at the same time that the visual stimulus is offered to the user. Thus, it is speculated that the use of 3D Sandplay can facilitate the understanding of abstract concepts and, at the same time, promote the sensorial integration in people with DS. It is because the execution of the proposed activities requires the manipulation of a tangible interface, whose texture, color, and shape are modified in consonance with the visual and spatial perception of the user. 3D Sandplay was evaluated by a group of 28 volunteers from the Alfadown project at PUC Goiás in Goiânia. In summary, this article reports the results of an observational study, with a descriptive approach, with an exploratory objective, with field research, using an evaluation questionnaire proposed by the authors, as an instrument for data collection. This work is part of the project titled "Down Syndrome and Autistic Spectrum Disorder: Researching Families to Understand the Impact of Disability on Parents and the Support Offered", authorized by the Research Ethics Committee, through the Certificate of Presentation for Ethical Assessment (in Portuguese, CAAE): 51159415.3.0000.0037.

This section aimed to present the theme, the object of study, and the main justifications that guided the achievement of this work. In Section 2, we present the materials and methods, with the description of the technologies and prototypes, processes and test scenarios, used for the data collection. Section 3 presents the results of the tests and the discussion of these results. In Section 4, aspects related to the originality, complexity, and usefulness of this work are analyzed. Also, proposals for future work are presented.

\section{MATERIALS AND METHODS 2.1 Development of the 3D Sandplay System}

The development of 3D Sandplay was based on the incremental bottom-up model. During the application of the process, three prototype versions of the system were built. This model was used due to the need to refine the requirements and the customization of components and technological resources available in the embedded systems laboratory at PUC Goiás. Fig. 1 illustrates and synthesizes the process used for the development of 3D Sandplay through an activity diagram.

The process of requirement analysis was performed through discussions, in weekly meetings, together with all project participants. The team has an interdisciplinary background, is made up of specialists in Speech Therapy, Psychology, and Computing. After the first step of the "Application requirements" activity, the prototype construction started concurrently, subdivided into software and hardware. At each new stage of this activity, further improvements were incorporated into the prototypes. At the end of the third version, the prototype was made available for testing with people with DS.

The activity "White Box Tests" was performed, to find possible logic and coding errors in the software. Then, in the "Black Box Tests" activity, the system calibration was performed to adjust the software to the hardware.

During the "Usability Test" activity, tests were developed and applied in people with DS. The entire testing process was specified and approved by the ethics committee, including the instrument for data collection, parental consent, and the consent of volunteers. Also, all activities were defined, programmed, and embedded in 3D Sandplay, to avoid flaws and minimize risks to the research volunteer, participants of the Alfadown project. Section 2.3.1 describes this activity in details.

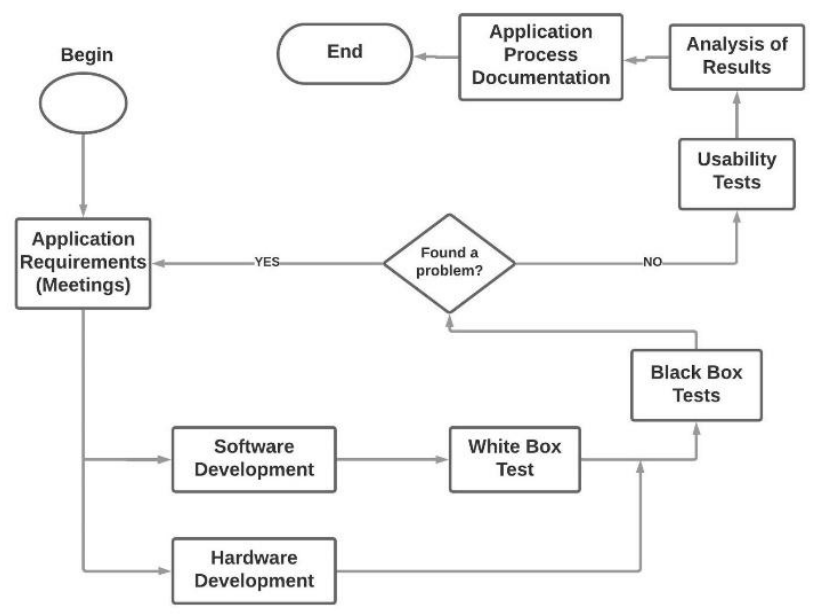

Fig 1: Activity diagram of the application development process

\subsection{Prototypes and Technologies}

The 3D Sandplay system required the development of hardware and software for a specific purpose application whose initial requirement was to develop a system capable of stimulating the motor coordination and cognitive development of people with DS through Sandplay AR technology. For the software development, the ARSandbox library Kreylos [8], was freely available under the terms of the GNU (General Public License) and published by the Free Software Foundation. In addition to this, the Magic Sand library, version 1.5.4.1 [9]. The Windows 10 operating system, 32-bit version, was the chosen support platform for its availability, ease of use, and no intermittent failures during black-box testing. Figure 2 shows some graphical elements that make up the software embedded in 3D Sandplay, for the activities performed with SD people. This image was obtained from the projection on the surface of the sandbox, an integral part of the hardware.

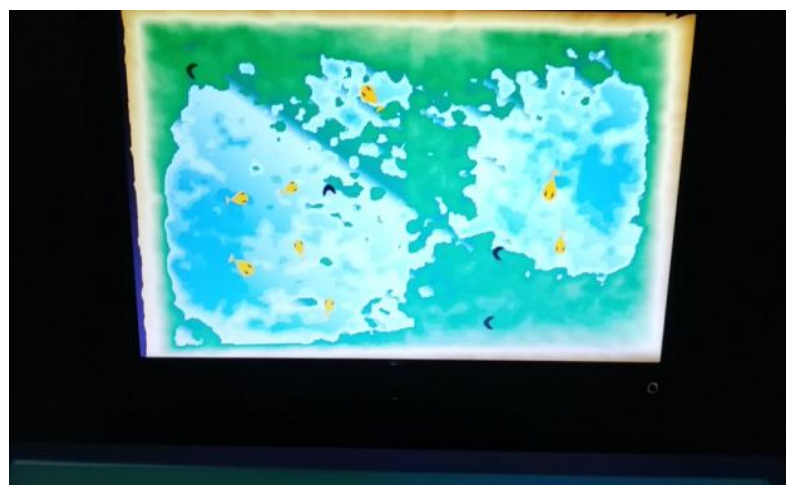

Fig 2: Some graphical features for visual screening in 3D Sandplay

Hardware development was based on (i) portability, ease of assembly and disassembly and transport of the prototype; (ii) low cost, by the reuse and integration of commercially available electronic components, of the lower price, when 
compared to those recently launched in the market. For this, the Microsoft Kinect sensor version 1.0 (Microsoft, 2010), a multimedia projector LED Projector, model YG-300 (Salange Technology, 2014) was selected and used. Besides, a microcomputer with an integrated NVIDIA GM 107 GeForce GTX 750 graphics card, Intel Core i5-3330 CPU @ 3,000 GHz, 8 GB RAM (DDR3 $1600 \mathrm{MHz}$ ) and secondary memory of 1 TeraByte was used.

Kinect, version 1.0, has color and depth detection lenses, for a horizontal field of view of 57 degrees and a vertical of 43 degrees. Also, the depth sensor range is 1.2 to 3.5 meters and captures up to 20 movements per active user. The projector offers 1920 by 1080 pixels resolution, with projection size equal to 60 inches and a projection incidence of 60 lumens. The projector is 20 centimeters long, 18 centimeters wide, 8 centimeters deep, and masses of $0.6 \mathrm{~kg}$.

Fig. 3 illustrates the hardware and presents the three versions of the same prototype. Figure 3 (a) shows the first version, constructed after the first step for defining the requirements. In this version, the dimensions used for the litter box were: 45 $\mathrm{cm}$ long, $33 \mathrm{~cm}$ wide and 7 inches high. The structure was 90 centimeters tall but did not adequately fill the projection region in the litter box. Afterward, the support of the Kinect sensor and the multimedia projector were redesigned to become more stable and reducing the occupied space, Figure 3 (b). Besides, the sand type was replaced to increase the reflection and improve the projection, and the sandbox dimensions were increased. In the final version, the metallic structure was galvanized, and the color adjustment used in the finish, Figure 3 (c).

For the calibration process of the prototype, it was necessary to obtain the Cartesian coordinates of the sandbox manually. For this, a tool was developed in the format of a paper disk, 12 centimeters in diameter. This tool must be moved in all directions of the space in which the sandbox is contained. After the measurements, the software calculates the coordinates representing the region of interest, establishing the operating range for the depth sensor. For the second version of the prototype, the software automatically exits the calibration using only the data generated by the sensor and the multimedia projector.

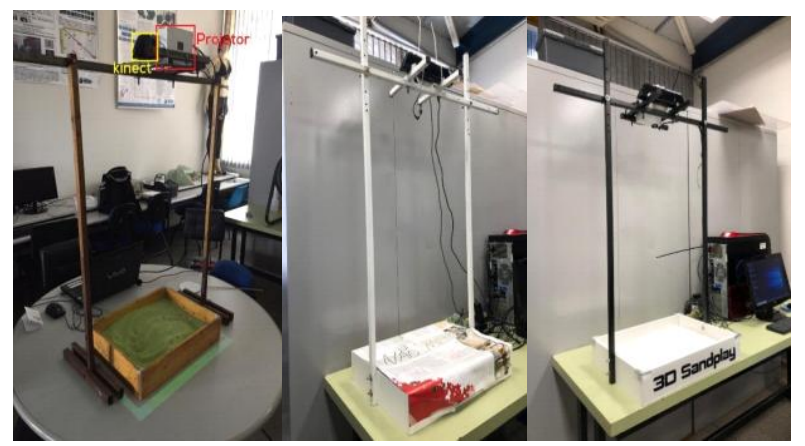

Fig 3: Versions of the prototype. (a) First version; (b) Second version; (c) Third version.

\subsection{TESTS}

\subsubsection{SYSTEM TESTS}

System tests, or black-box tests, were proposed to evaluate the operating range of 3DSandplay. For this, four scenarios were considered, whose luminous incidence was controlled and adjusted. Figure 4 (a) shows the projection for luminous incidence equal to 175 LUX, Figure 4 (b) for 168 LUX, Figure 4 (c) for 80 LUX and Figure 4 (d) for 22 LUX. The purpose of these tests was to verify the projection capacity of the system. For the test with a luminous incidence equal to 20 LUX, shown in Figure 4 (d), the projection under the surface of the sandbox was shown to be sharper. Obviously, the smaller the ambient lighting, the greater the quality of the image projected on the surface of the sand. In the tests performed with the research volunteers the ambient illumination was adjusted to approximately 100LUX.
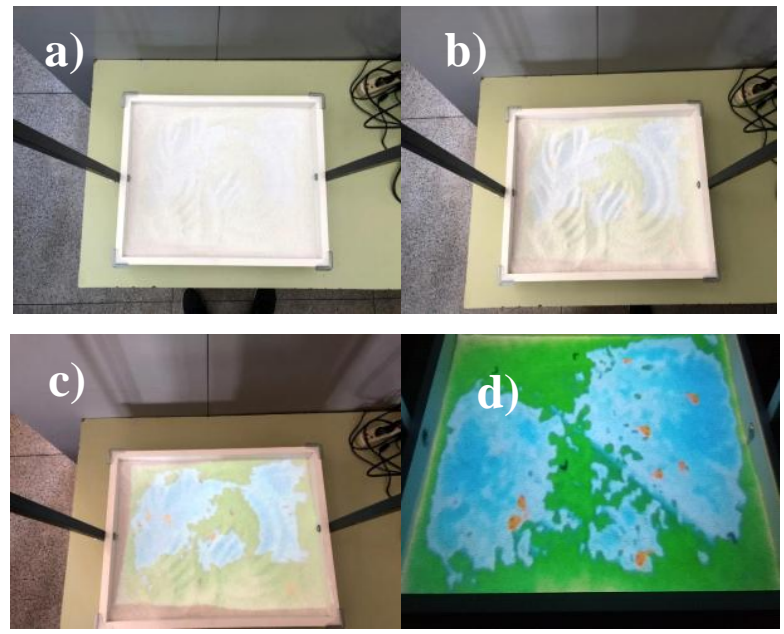

Fig 4: Test of light incidence in the environment. (a) 175 LUX; (b) 168 LUX; (c) 80 LUX and (d) 22 LUX.

\subsubsection{VOLUNTARY TESTS OF THE ALFADOWN PROJECT}

Tests with volunteers, people with DS, participants in the Alfadown project occurred after the parents or guardians signed the Free and Informed Consent Term (TCLE). These were individually approached for the presentation of the project, reading and clarification of the TCLE and, if they agree, authorized the participation of the child.

At the time of data collection, on the days that the volunteers participated in activities in the Alfadown project, the participants were individually taken to a reserved room, with presence available to parents and caregivers. After that, the researchers presented the 3D Sandplay and the activity in which the volunteer would be submitted. The researchers then asked the volunteers about their understanding of the event and whether they would like to participate. The nod was recorded, and the volunteers who did not wish to attend were returned to the classroom. Participants who did not use oral language and those who had motor difficulties or other comorbidities that prevented interaction with the researchers or the system were excluded from the tests.

To apply the tests and collect the necessary information, a questionnaire, completed by a speech-language pathologist, was elaborated during the execution of the activities. The survey consists of five questions, with space for observations. The first question refers to the performance of the activities proposed to the research volunteers. They were given models, by images projected on a video monitor. Then they were asked to replicate the model in the sandbox. Figure 5 shows the evaluation questionnaire used during the data collection. 


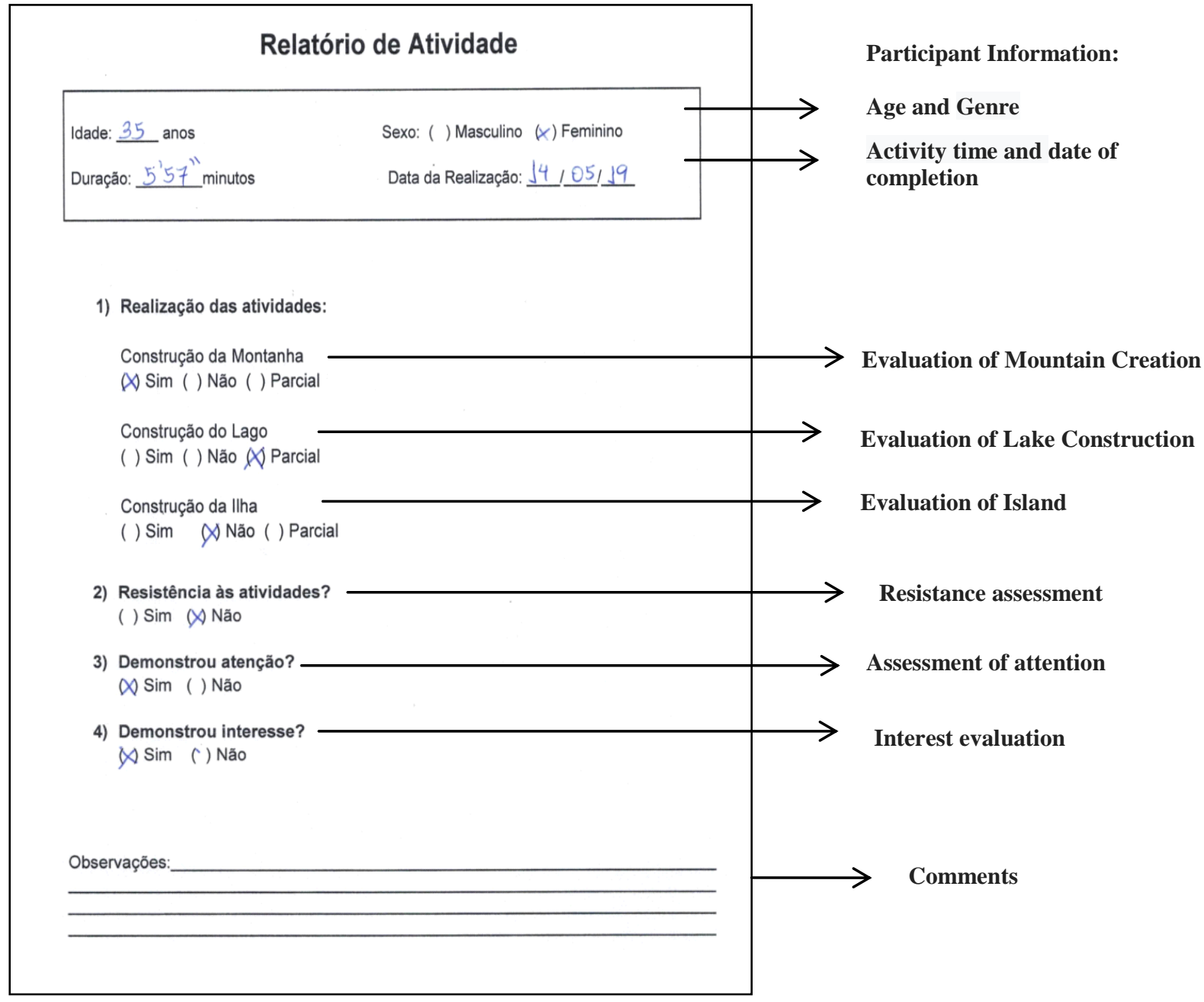

Fig 5: Test activity report

With the other questions (Figure 5), it was verified whether the volunteer showed resistance, showing discomfort or rejection to manipulate the sand, maintained the focus of vision in the activity, by the visual attention and showed interest, by curiosity or satisfaction during the execution of operations. Due to the duration of the events, objective answers were chosen, with two or three states, yes, not or partially, only to evaluate the execution of the activities. It facilitated the observation and the score of the evaluator, who completed the evaluation questionnaire. The same evaluator fills all forms. Figure 6 shows the test environment during the execution of the first activity requested for each volunteer, referring to the construction of a small-scale mountain by the manipulation of sand in the sandbox. In this figure, it is possible to observe different shades of color as the participant changed the relief. Lighter colors are projected on the shallower surface, while darker colors, predominantly brown, on the steeper surface. In this activity, the comprehension and execution by the motor coordination presented by the participant to achieve the final result. In the same way, the subsequent events were evaluated, referring to the construction of a lake and the construction of an island.

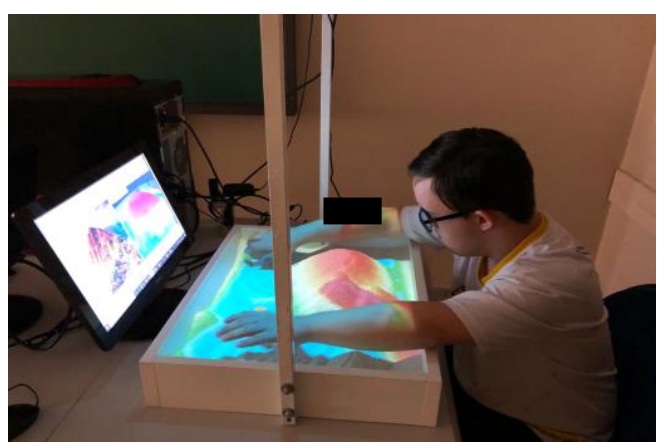

Fig 6: Test run by a volunteer.

Figure 7 presents the test process through an activity diagram. It is possible to identify the activities and the sequence of execution for the accomplishment of the events. Initially, the system was installed and configured. Then the volunteers were led to the tests where they were instructed about the activities, granted consent, and then the experiments were performed. After that, the questionnaire was completed, and the volunteer was reappointed to the activities of the Alfadown project. 


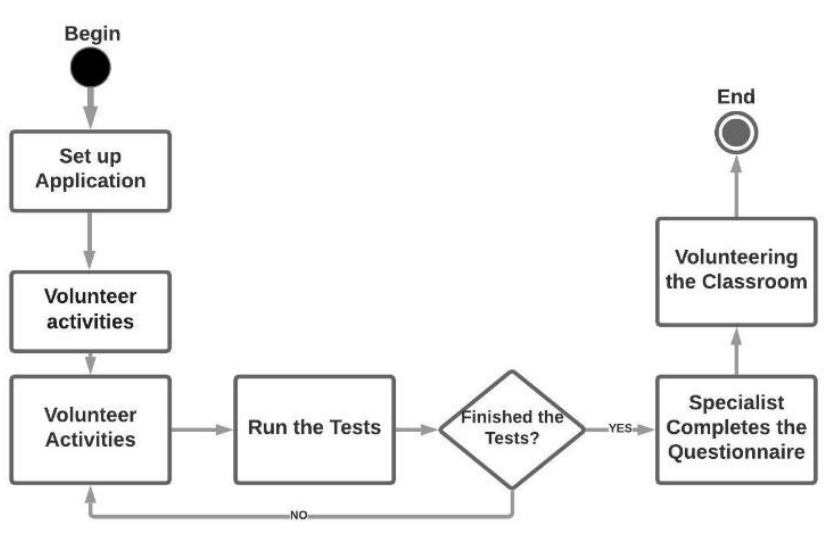

Fig 7: Testing processes.

\section{RESULTS AND DISCUSSION}

Usability testing was performed in three sessions, for two weeks, so that the sample size was maximized. Then the data were extracted from the tabulation questionnaires, and the central trend measures were calculated. For this study, 28 volunteers of both sexes, aged between 6 and 51 years participated. Figure 8 shows the results obtained for the execution of the requested activities of the research volunteers. Activity 1 refers to the construction of the mountain, Activity 2 to the creation of a lake and Activity 3 refers to the nature of an island. The results show that there was a proportional variation related to the increase in the difficulty imposed by the activities, both in the intellectual scope, by the rise of the abstraction of the evaluated concepts, and the required motor coordination. For this, it is necessary to consider that Activity 1 is less complicated compared to Activity 2 and Activity 3. None participant was unable to construct the lake, although the number of participants who performed this activity partially increased compared to Activity 1. Many participants (44.4\%) had difficulty creating shallow surfaces by digging the sand so that the projection system can identify the gradient and fill it in blue to represent water. Likewise, for Activity 3 . Figure 9 shows the results for behavioral evaluation during the execution of the activities. Attention refers to the engagement and, mainly, the visual focus, observed of each volunteer, during the performance of the activities. Interest was perceived by the demonstration of

Table 1: Results in each activity by age group.

\begin{tabular}{|c|c|c|c|c|c|c|c|c|}
\hline \multirow[b]{2}{*}{ Age Group } & \multicolumn{2}{|c|}{ deffinifint } & \multicolumn{2}{|c|}{ deffintift } & \multicolumn{2}{|c|}{ Iftentifing } & \multicolumn{2}{|c|}{ 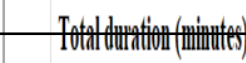 } \\
\hline & Success & $R F$ & Sulcess & $R F$ & Success & $R F$ & Iotal & Alernge \pm sd \\
\hline Child/Adolescent (6.17) & 7 & 63,60 & 6 & 54,54 & 1 & 9,09 & 11 & $4,95=3,05$ \\
\hline Adultifio:31) & H & 81, & f & 5605 & 7 & 43.8 & 16 & $-4.21-1.60$ \\
\hline & & & & & & & & \\
\hline
\end{tabular}

Table 2: Results in each activity by gender.

\begin{tabular}{|c|c|c|c|c|c|c|c|c|}
\hline \multirow[b]{2}{*}{ Gellle } & \multicolumn{2}{|c|}{ Activity 1} & \multicolumn{2}{|c|}{ Activity? } & \multicolumn{2}{|c|}{ Activity 3} & \multirow{2}{*}{ Iotal } & \multirow{2}{*}{$\begin{array}{c}\text { Total dullation (minutes) } \\
\text { Avernge } \pm \text { sd }\end{array}$} \\
\hline & Success & $R F$ & Sulceess & $R F$ & Silceess & $R F$ & & \\
\hline Male & 12 & 75 & 10 & 625 & 4 & 25 & 16 & $4,7 \pm 2,71$ \\
\hline Fenale & 8 & 72,7 & j & 45,45 & 4 & 36,4 & 11 & $4,39 \pm 2,33$ \\
\hline
\end{tabular}

fascination, pleasure, and satisfaction in performing a given activity. The Resistance considered discomfort, aversion, or immediate refusal to manipulate the sand.

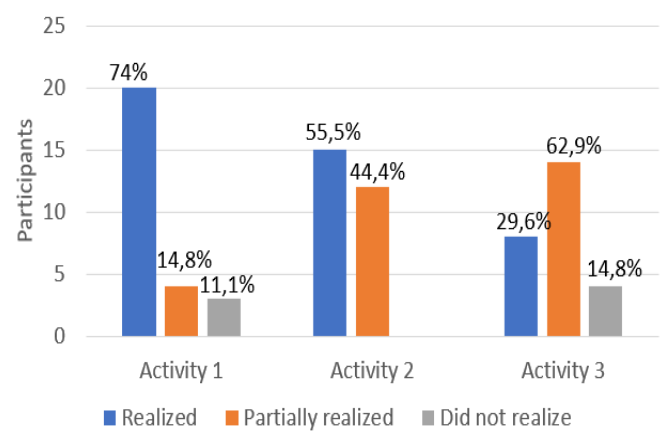

Fig 8: Execution of Activities.

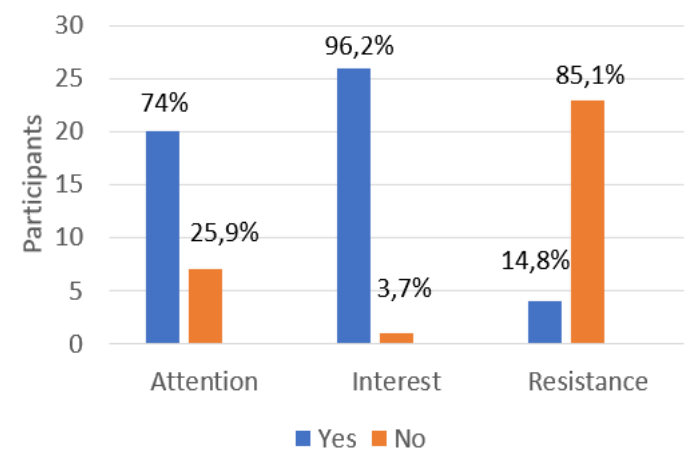

Fig 9: Attention, Interest, and Resistance.

Tables 1, 2 stratify the data by age group and gender to perform the activities proposed to the volunteers, while Table 3 and 4 stratify the data to present the results of the observed variables that reflect the behavior of the volunteers, during the execution of the activities. The number of correct answers by the group of people older than 18 years for Activities 1 and 2 was higher when compared to children and adolescents and may be associated with the Attention shown in Table 3. Of course, cognitive and motor development is higher in adults, when compared to children and adolescents. In particular, in those who received early stimulation. No other distortions were observed.

Table 3: Attention, Interest, and Resistance by age group.

\begin{tabular}{|c|c|c|c|c|c|c|c|}
\hline & \multicolumn{2}{|c|}{ Aftentifion } & \multicolumn{2}{|c|}{ Intetest } & \multicolumn{3}{|c|}{ Reststater } \\
\hline Age Gloup & Partipants & RF & Participants & $R F$ & Porticipants & $R F$ & Total \\
\hline Child/ Adolescent (6-17) & 6 & 54,54 & 11 & 100 & 2 & 18.18 & 11 \\
\hline Adultt(18.51) & 14 & 87,5 & 15 & 93,75 & 2 & 12,5 & 16 \\
\hline
\end{tabular}

Table 4: Attention, Interest, and Resistance by gender.

\begin{tabular}{|c|c|c|c|c|c|c|c|}
\hline \multirow[b]{2}{*}{ Genle } & \multicolumn{2}{|c|}{ Attentitiont } & \multicolumn{2}{|c|}{ Interest } & \multicolumn{2}{|c|}{ Restistatitet } & \\
\hline & Participants & $R F$ & Participants & RF & Participants & $R F$ & Total \\
\hline Male & 10 & 62,5 & 15 & 93,75 & 2 & 12,5 & 16 \\
\hline Fentitet & 10 & 90,9 & 11 & 100 & 2 & 18,1 & H \\
\hline
\end{tabular}




\section{CONCLUSION}

This paper proposes a tool for the training, rehabilitation, and entertainment of people with DS. It provides computational resources that increase the perception and tactile stimulation during the execution of activities. With this, it is possible to promote sensory integration and at the same time to use the tool itself as a reinforcer, particularly crucial for therapies whose behavioral analysis is applied. At this moment, no records of the use of AR Sandplay in population with Down syndrome have been found. The results presented in Section 3 reveal the great potential for this technology in people with DS. In addition, the system shown in this work demonstrates that the development of Sandplay AR technology, in the scope of a university extension project, by the integration of shelf components and by the use of free software, allows a reduction of up to 10 times in cost for acquisition of a similar system when compared to commercially available products, discounted taxes. However, the project described in this paper can easily be replicated in other institutions for SD population activities.

In future works, long-term activities should be evaluated, comparing the results obtained by 3D Sandplay users with a control group. Also, a channel for biofeedback should be incorporated into the 3D Sandplay by tracking facial movements. With this, it is possible to quantify variables that reflect the behavior of the user over time. Besides, activities can be customized online, during execution, by software adjustments demanded by the response obtained by the user. For this, it is necessary to adapt this technology to environments with low luminous intensity.

\section{ACKNOWLEDGMENTS}

This work was supported by the people involved with the Alfadown project. In particular, Pollyanna Rosa Ribeiro and Renata Barreto.

\section{REFERENCES}

[1] ISHII, H. Tangible bits: beyond pixels. In Proceedings of the 2nd International Conference on Tangible and Embedded interaction (Bonn, Germany, February 18 20,2008). TEI '08. ACM, New York, 2008.

[2] SCOZ, Beatriz. O Jogo de Areia (Sandplay): subjetividade e produção de sentidos. Periódicos eletrônicos em Psicologia, Rio de Janeiro, 2008. Available

http://pepsic.bvsalud.org/scielo.php?script=sci_arttext\&p id=S1806-58212008000100005.

[3] ANTUNES, Elaine; VICENTINI, Carolina. DESENVOLVENDO A SENSIBILIDADE SENSORIAL TÁTIL PLANTAR EM PORTADORES DE AUTISMO INFANTIL ATRAVÉS DO "TAPETE SENSORIAL" - ESTUDO DE TRÊS CASOS. Caderno Brasileiro de Terapia Ocupacional, São Carlos, v. 5, n. 1, p. 47-52, 2005. Caderno de Terapia Ocupacional da UFSCar, 2005, vol, 13 n 1.

[4] PANTUWONG, Natapon; CHUTCHOMCHUEN, Napat; WACHARAWISOOT, Patphimon. Interactive Topography Simulation Sandbox for Geography Learning Course. In: ICITEE 2016: THE 8TH INTERNATIONAL CONFERENCE ON INFORMATION TECHNOLOGY AND ELECTRICAL ENGINEERING, 8., 2016, Yogyakarta, Indonesia. Atas [...]. Indonesia: IEEE, 2016.

[5] PUC, Goiás. (2018) [Online]. Available in: http://sites.pucgoias.edu.br/extensao/coordenacoes/coord enacao-de-extensao/programa-de-referencia-eminclusao-social/.

[6] Lima, D. et al. "Software with Biofeedback to Assist People with Down Syndrome". International Journal of Computer Applications, v. 158, p. 31-37, 2017.

[7] Santos, D. A. A. et al. "Wearable device for literacy activities with people with down syndrome". In: 2017 IEEE MIT Undergraduate Research Technology Conference (URTC), 2017, Cambridge. 2017 IEEE MIT Undergraduate Research Technology Conference (URTC), 2017. p. 1

[8] KREYLOS, Oliver. AR Sandbox. California, 2017. Available in: http://idav.ucdavis.edu/ okreylos/ResDev/SARndbox/Li nkDownload.html.

[9] KOGAN, Gene; WOLF, Thomas; PAULSEN, Rasmus R. Magic Sand. califórnia, 2018. Available in: https://github.com/thomwolf/Magic-Sand 